\begin{abstract}
Implicit in many discussions of labour market policy is the assumption that, in the absence of interventions, the operation of the labour market is well-approximated by the perfectly competitive model. The merits or demerits of particular policies is then seen as a trade-off between efficiency and equality. This paper analyses the impact of a variety of policies - the minimum wage, trade unions, unemployment insurance, progressive income taxation and restrictions on labour contracts - on efficiency when labour markets in the absence of intervention are monopsonistic and not perfectly competitive. A simple version of the Burdett and Mortensen (1998) model is used for this purpose.
\end{abstract}

JEL classification: J0

Key words: Labour market policy, Monopsony

\title{
Acknowledgements
}

I would like to thank seminar participants at the University of Essex and the MacArthur Foundation Network on the Effects of Inequality on Economic Performance for their comments.

Alan Manning is director of the Labour Markets programme at the Centre for Economic Performance, London School of Economics and Professor of Economics in the Department of Economics, LSE.

Published by

Centre for Economic Performance

London School of Economics and Political Science

Houghton Street

London WC2A 2AE

(C) Alan Manning, submitted August 2001

ISBN 0753015439

Individual copy price: $£ 5$ 


\section{Monopsony and the Efficiency of Labour Market Interventions}

\section{Alan Manning}

Introduction 1

1. Monopsony in the Labour Market 2

2. The Free Market Equilibrium 6

3. The Minimum Wage and Trade Unions 8

4. Unemployment Benefits 9

5. Progressive Income Taxation 11

6. Restrictions on Labour Contracts 12

$\begin{array}{lll}7 . & \text { Conclusions } & 16\end{array}$

$\begin{array}{ll}\text { Figures } & 17\end{array}$

$\begin{array}{ll}\text { Appendix } & 19\end{array}$

References $\quad 24$ 


\section{Introduction}

Debates about the desirability and consequences of labour market interventions continue to be at the heart of many policy debates about the way in which modern industrialised economies should be run. The most prevalent opinion among economists is that, in the absence of interventions, the operation of labour markets is well approximated by the perfectly competitive model. This view, when combined with the fundamental theorems of welfare economics, results in a presumption of efficiency in the free market unless proved otherwise and an innate suspicion of interventionist policies. To be sure, there are many individual papers that identify reasons why the free market may not be efficient but these papers tend to be issue-specific and there is no single unifying model to rival that of the perfectly competitive model which continues to have a powerful hold over the minds of economists. As a result, debate about the merits of intervention is often put in terms of a trade-off between efficiency and equality with those economists favouring a more interventionist approach tending to be those who have a welfare function that puts greater weight on equality and/or those who believe the efficiency cost of equality is relatively low.

Empirical research helps to provide evidence on the impact of interventions that informs economists' views about the relevant trade-offs, but empirical research finds it hard to say much about efficiency issues and the presumption that interventions reduce efficiency dominates (explicitly or implicitly) much thinking. In Samuelsons dictum "in economics, it takes a theory to kill a theory; facts can only dent a theorists hide" and that view motivates this paper.

It tries (perhaps over-ambitiously) to provide a rival to the perfectly competitive model as a tool to analyse the efficiency of labour market interventions. It sets up a simple, theoretical, imperfectly competitive model of the labour market (based on the wage-posting model of Burdett and Mortensen, 1998) and uses that model to address a whole range of labour market interventions, namely:

- $\quad$ minimum wages

- policies to encourage trade unions

- unemployment insurance to support those whose labour market earnings are low or non-existent

- progressive tax systems

- policies like restrictions on hours or health and safety legislation to limit the form of contracts that can be signed between employers and workers.

The theoretical model assumes that 'free' labour markets are better thought of as monopsonistic 
rather than perfectly competitive. As many (if not most) labour economists are sceptical about the relevance of monopsony, some justification for this assumption is needed. Manning (2001) provides a lengthy and detailed argument but the basic argument can be summarised very briefly: the perfectly competitive model makes the unbelievable assumption that a wage cut of a cent immediately causes all workers to leave the firm. However, there are good reasons to believe that labour markets have substantial frictions as it is costly for workers to change jobs and employers to find workers. These frictions mean there are generally rents in the employment relationship and that cutting the wage will not lead to an immediate quit giving employers some monopsony power.

The paper shows that, in monopsonistic labour markets, one can prove surprisingly strong results about the beneficial efficiency effects at the margin of most (though not all) of the labour market interventions listed above. This should not be taken to imply that these policies are always good, just that they are not always bad. The presumption of economists should be that these policies are desirable and the debate about the appropriate level of intervention.

The plan of the paper is follows. The next section outlines the basic model of a monopsonistic labour market that we will use in the theoretical part of the paper. It is a simplified version of a model by Burdett and Mortensen (1998). We then use this model to analyse the impact of a number of typical social democratic interventions: the minimum wage, trade unions, welfare benefits, progressive income taxation and restrictions on the legal form of labour contracts. We show that ones view of these policies is always more positive if one starts from a monopsonistic perspective though this should not be taken to mean that these policies are always good, just that one should not have the instinctive reaction that they are automatically bad.

\section{Monopsony in the Labour Market}

If there are rents from frictions, one needs to have some view of the way in which they are divided. The wage-posting model of Burdett and Mortensen (1998) assumes that employers set wages and the model of this paper is based on theirs. ${ }^{1}$

\footnotetext{
${ }^{1}$ Perhaps the most common alternative model used is ex post bargaining between worker and employer (e.g. Pissarides, 1990 or Burdett and Mortensen, 1998, for a comparison). In many situations, the bargaining and wage-posting models have the same predictions but there are cases (see below) where there are important differences. For low-wage labour markets, wage-posting seems a more appropriate as sumption: e.g. Machin and
} 
We will start with the case where the number of workers and employers are fixed and in which the wage offer distribution is exogenously fixed. The basic assumptions are:

(A1) Workers: There are $M_{w}$ workers all of whom are equally productive and attach equal value, $b$, to leisure. They seek the job with the highest wage.

(A2) Employers: There are $M_{f}$ employers, each of which is assumed to be infinitesimally small in relation to the market as a whole. All employers have constant returns to scale, the productivity of each worker being $p$. For future use, denote the ratio of firms to workers by $M=M_{f} / M_{w}$.

(A3) Matching Technology: Both employed and unemployed workers receive job offers at a rate ?(M) where ?'(M)>0 and $\varepsilon_{\lambda M}<1$. Job offers are drawn at random from the set of firms. Employed workers leave their jobs for unemployment at an exogenous job destruction rate $d_{\mathrm{u}}$. All workers, both employed and unemployed, leave the labour market at a rate $\mathrm{d}_{\mathrm{r}}$, to be replaced by an equal number of workers who initially enter unemployment. Define $d=d_{u}+d_{r}$.

(A4) Wages: For reasons that are explained in more detail in Burdett and Mortensen (1998), (and will be briefly discussed later) the equilibrium will have a wage distribution. Denote the cumulative density function of wages across employers by $\mathrm{F}(\mathrm{w})$ and the associated density function by $\mathrm{f}(\mathrm{w})$. For future use, denote the inverse of $\mathrm{F}(\mathrm{w})$ by $\mathrm{w}(\mathrm{F})$. For the moment, treat this as exogenous though the bulk of the paper will be about how different interventions affect the wage offer distribution. In some of what follows, taxes will drive a wedge between the wage paid by employers and that received by workers: so denote by $\mathrm{w}_{\mathrm{c}}(\mathrm{F})$ the consumer wage received by workers in an employer at position $\mathrm{F}$ in the wage distribution.

These assumptions have been chosen to be the simplest possible whilst retaining the essential features of a monopsonistic labour market in which a higher wage reduces the separation rate and raises the recruitment rate. The following Proposition provides some useful preliminary results.

\section{Proposition 1}

In the labour market with fixed numbers of workers and employers:

1. Employment in the firm at position $\mathrm{F}$ in the wage distribution is given by:

$$
N(F)=\frac{\delta \lambda(M)}{M[\delta+\lambda(M)(1-F)]^{2}}
$$

Manning (1997) found that one-third of UK residential care homes chose to pay all their care assistants exactly the same hourly wage, an outcome that would be hard to explain in terms of ex post bargaining. 
2. The employment rate, $\mathrm{n}$, in the economy is given by:

$$
n=\frac{\lambda(M)}{\delta+\lambda(M)}
$$

3. The expected level of profits, $E(\pi)$, is given by:

$$
E(\pi)=\frac{\lambda[p-E(w)]}{M(\delta+\lambda)}
$$

where $\mathrm{E}(\mathrm{w})$ is the expected wage paid by employers.

4. The value of being unemployed, $\mathrm{V}^{\mathrm{u}}$, is given by:

$$
\delta_{r} V^{u}=b+\frac{\lambda\left[E\left(w_{c}\right)-b\right]}{\delta+\lambda}
$$

where $\mathrm{E}\left(\mathrm{w}_{\mathrm{c}}\right)$ is the expected wage received by workers.

Proof: See Appendix.

The intuition behind Proposition 1 is simple. (1) says that employment in a firm is determined by the overall ratio of firms to workers (M) and by the position in the wage distribution (as high-wage firms have lower separation rates and find it easier to recruit). The overall employment rate as given by (2) is simply determined by inflow and outflow rates. (3) and (4) say that both expected profits and value of being in the labour market are determined by expected wages. The expression for workers in (4) has a simple intuition. The employment rate is given by (2) so the final term in (4) is the probability of being in employment multiplied by the expected surplus when in employment.

Now consider the case (not analysed by Burdett and Mortensen, 1998) where the supply of both workers and employers to the labour market is not completely inelastic. For firms, we will assume that there is a cost of entry $\mathrm{C}_{\mathrm{f}}$ which, to give some flexibility in the model about the elasticity in the supply of firms, will be assumed to vary across potential employers. Denote by $C_{f}\left(M_{f}\right)$ the value of $C_{f}$ for the marginal employer if there are $\mathrm{M}_{\mathrm{f}}$ employers. Then, in the free entry equilibrium, and using (3), we must have:

$$
E(\pi)=\frac{\lambda(M)[p-E(w)]}{M(\delta+\lambda(M))}=C_{f}\left(M_{f}\right)
$$

On the worker side, we will use an analogous method of introducing some elasticity into the labour supply by assuming that there is a 'participation' cost of $\mathrm{C}_{\mathrm{w}}$ that must be paid each period. If the worker does not pay it then they cannot be employed or get a job offer. This is a stylised way of introducing some elasticity into labour supply but one could imagine it as the (amortised) cost of acquiring skills necessary for employment before labour market entry. We will assume that $\mathrm{C}_{\mathrm{w}}$ varies 
across workers: denote by $C_{w}\left(M_{w}\right)$ the value of $C_{w}$ for the marginal worker if there are $M_{w}$ workers in the labour market. The free entry condition for workers can be derived as follows.

Let us distinguish between the value of being unemployed $\mathrm{V}^{\mathrm{u}}$ and the value of non-participation $\mathrm{V}^{\mathrm{n}}$ which, as non-participants are always unemployed and save the cost of participation, can be written as:

$$
\delta_{r} V^{n}=b+C_{w}
$$

Free entry of workers means that, in equilibrium, we must have $\mathrm{V}^{\mathrm{u}}=\mathrm{V}^{\mathrm{n}}$ for the marginal worker so that, using (4), the 'free entry' condition for workers can be written as:

$$
\frac{\lambda(M)\left[E\left(w_{c}\right)-b\right]}{\delta+\lambda(M)}=C_{w}\left(M_{w}\right)
$$

For fixed wages, the free entry equilibrium then involves solving (5), (4) and (8) for $\mathrm{M}_{\mathrm{w}}$ and $\mathrm{M}_{\mathrm{f}}$. The simplest way to see that there is a unique equilibrium (for a given level of average wages) is to note that (7) implies a positive relationship between $M$ and $M_{w}$ as the greater the ratio of employers to workers the higher is the employment rate. And, as long as the elasticity of $\lambda(M)$ with respect to $M$ is less than one, (5) implies a negative relationship between $M_{f}$ and $M$ as the greater the ratio of employers to workers the lower is employment per firm. Using $M=M_{f} / M_{w}$ we can eliminate $M_{f}$ from (5) to have a negative relationship between $\mathrm{M}_{\mathrm{w}}$ and $\mathrm{M}$. The supply of firms (5) is represented by FF in Figure 1 and the supply of workers in (7) by WW.

The distribution of the entry costs for employers and firms determines the elasticity of the FF and WW lines. For example, if all firms have the same entry costs then the supply of firms to the market is perfectly elastic and the FF lines are vertical. If, on the other hand the supply of labour to the market is inelastic then WW will be horizontal. But, it should be apparent that the set-up used here encompasses a wide range of possibilities: this helps to ensure that none of the conclusions will be sensitive to assumptions made about elasticity in the supply of firms or workers to the market.

One might wonder about the efficiency of the equilibrium. We will not worry about distributional issues and will just focus on the total surplus, $\mathrm{S}$. This can be written as:

$$
S=\frac{\lambda(M)(p-b)}{\delta+\lambda(M)} M_{w}-\int_{0}^{M}{ }^{w} C_{w}\left(m_{w}\right) d m_{w}-\int_{0}^{M} f C_{f}\left(m_{f}\right) d m_{f}
$$

The first term is the surplus from employment and the other terms the costs of participation of employers and workers. The following Proposition provides some first-order conditions for the efficient levels of $\mathrm{M}_{\mathrm{f}}$ and $\mathrm{M}_{\mathrm{w}}$. 


\section{Proposition 2}

1. The first-order conditions for the efficient numbers of employers and workers can be written as:

$$
\begin{gathered}
\frac{\delta \lambda(M)[p-b]}{M[\delta+\lambda(M)]^{2}} \varepsilon_{\lambda M}=C_{f}\left(M_{f}\right) \\
\frac{\lambda(M)^{2}[p-b]}{[\delta+\lambda(M)]^{2}}\left[1+\frac{\delta}{\lambda}\left(1-\varepsilon_{\lambda M}\right)\right]=C_{w}\left(M_{w}\right)
\end{gathered}
$$

where $\mathrm{e}_{? \mathrm{M}}$ is the elasticity of ?(M) with respect to $\mathrm{M}$.

2. If the expected producer and consumer wages are equal then both efficiency conditions will be satisfied if:

$$
E(w)=p-\frac{\delta}{\delta+\lambda} \varepsilon_{\lambda M}(p-b)
$$

Proof: see Appendix.

This shows that an appropriate level of average wages can satisfy the efficiency conditions for both the entry of firms and the entry of workers. If the expected wage is higher (lower) than the efficient level there will be excessive entry of workers (firms) and insufficient entry of firms (workers).

So far, the distribution of wages has been treated as exogenous. But, let us now consider whether the free market attains these efficiency conditions or whether wages will be too high or too low.

\section{The Free Market Equilibrium}

In this section we assume that employers set wages to maximise profits. This is the equilibrium considered by Burdett and Mortensen (1998) so we shall only discuss it briefly here. They show that the only possible equilibrium is a wage distribution without mass points: the reason being that if there is a mass point in the wage distribution then an employer who deviates by paying a wage $\varepsilon$ higher will have only infinitesimally lower profits per worker but a much higher level of employment as they will now be more attractive to all the workers in the firms at the mass point.

As all firms must, in equilibrium, make the same level of profits, the wage paid at position $\mathrm{F}$ in the wage offer distribution, $w(F)$, must satisfy:

$$
[p-w(F)] N(F)=[p-w(0)] N(0)
$$


where $\mathrm{w}(0)$ is the wage offered by the lowest-wage firm. Taking expectations of (12) we have that:

$$
[p-E(w)] E(N)=[p-w(0)] N(0)
$$

Using (1) and (2), (13) can be solved to yield the following expression for the average wage in the free market equilibrium:

$$
E(w)=p-\frac{\delta}{\delta+\lambda}[p-w(0)]
$$

so the average wage is a weighted average of marginal product and the lowest-wage offered.

Burdett and Mortensen (1998) show that the lowest wage offered in the free market equilibrium will be the reservation wage of unemployed workers. The reason is simple: there is no point in offering a lower wage as no workers will accept the job and there is no point in offering a higher wage (if one is the lowest wage firm) as one can lower wage costs without affecting the supply of labour to the firm. And, with job offers arriving at the same rate whether employed or unemployed, the reservation wage is simply equal to $b$, the value of leisure. Hence, in the free market we will have $w(0)=b$ and (14) becomes:

$$
E(w)=p-\frac{\delta}{\delta+\lambda}[p-b]
$$

so that the average wage is a weighted average of marginal product and the reservation wage. But, is the free market level of wages the efficient level: comparison of (14) and (11) readily leads to the following Proposition.

\section{Proposition 3}

If $\varepsilon_{\lambda M}<1$ then average wages are too low in the free market equilibrium.

Proof: Simple comparison of (14) and (11).

For a given value of $\mathrm{M}$, this Proposition implies that there are too many firms in the market, the reason being that excessive entry is encouraged by the monopsony profits on offer. In contrast, there are, for a given level of $\mathrm{M}$, too few workers in the market as they receive less than their marginal product.

However, one should not conclude that there are too few workers in the market compared to the first-best. Figure 2 makes it clear why. The line F'F' represents the entry conditions for firms when average wages are at their efficient level and FF when they are at the free market level. Similarly, W' W' represents the efficient entry condition for workers and WW the free market condition. M, the 
ratio of firms to workers, is clearly too high in the free market but $\mathrm{M}_{\mathrm{w}}$ may be too high or too low. For example, if $e_{? M}=0$ then $M_{w}$ is too low, but if $e_{? M}$ is close to one then $M_{w}$ is too high.

The rest of this paper is about whether we can restore efficiency through a suitable set of policies.

\section{The Minimum Wage and Trade Unions}

First, let us consider the introduction of a minimum wage of $\mathrm{w}_{\mathrm{m}}$ in this model. As long as this is above $\mathrm{b}$, this will be binding on the lowest wage firm in the market and will become the lowest wage paid. The expected wage distribution will be given by (14) with $\mathrm{w}(0)$ replaced by $\mathrm{w}_{\mathrm{m}}$. As the minimum wage raises average wages and free market wages are too low, it is not surprising that an appropriately chosen minimum wage can restore efficiency: the following Proposition tells exactly the wage that is necessary.

\section{Proposition 4}

A minimum wage, $\mathrm{w}_{\mathrm{m}}$, which satisfies:

$$
\frac{p-w_{m}}{p-b}=\varepsilon_{\lambda M}
$$

will lead to the socially optimal outcome.

Proof: This is the value of $\mathrm{w}_{\mathrm{m}}$ that makes (14) the same as (11).

The rule in (16) is similar to the result of Hosios (1990) for the efficient distribution of surplus in matching models with ex post bargaining rather than wage-posting. The Hosios rule for efficiency is that the workers share of the surplus should be equal to $\mathrm{e}_{\text {?M: }}$ : (16) says that this should be the workers' share of the surplus in the lowest-wage firm. But, importantly, workers in all other firms in the wage-posting model get a higher level of the surplus and this does affect one's interpretation. The Hosios result is often interpreted to say that the workers share of the surplus may be too high or too low for efficiency and there is no a priori reason to believe one case or the other. In contrast, this result says that, with wage-posting, there is an a priori case to believe that the workers' share of the surplus is too low and should be raised even though the share of the total surplus may be very high. Note, that this result does not say that minimum wages can be raised without limit without eventually reducing efficiency. If 
minimum wages are set at a level above that given by (16) then efficiency will be reduced. But, in contrast to the competitive model, minimum wages can be expected to be desirable over some range.

One could do a similar sort of analysis with trade unions. Modelling the impact of trade unions is time-consuming, as one has to specify union preferences and the nature of the bargaining between employers and unions. But, it is simple enough to see that if unions raise the average level of wages (a reasonable condition) then a certain amount of unionisation or union power can help move the free market towards efficiency.

\section{Unemployment Benefits}

In this section we consider the impact of paying welfare benefits to the unemployed. We start by assuming that all individuals not in employment (i.e. both the unemployed and the inactive) receive a payment $r$ when not in work, which is financed by a lump-sum tax, $t$, on those in work. ${ }^{2}$

The lowest wage firm must still make its workers indifferent between working (which pays $[w(0)-\tau]$ to workers and not working (who receive $[\mathrm{b}+\mathrm{r}]$ ): hence the lowest wage paid by employers must be $\mathrm{w}(0)=\mathrm{b}+\mathrm{r}+\mathrm{t}$. Substituting this into (14), the expected producer wage for firms is given by:

$$
E(w)=p-\frac{\delta}{\delta+\lambda}[(p-\tau)-(b+r)]
$$

It should readily be apparent that the unemployment insurance system will raise the average producer wage which can improve efficiency as it will move the FF line in Figure 2 towards the efficient F'F'.

However, it is not good for the incentives for workers to enter the labour market. The average consumer wage $\mathrm{E}\left(\mathrm{w}_{\mathrm{c}}\right)$ will be equal to $E\left(w_{c}\right)=E(w)-\tau$ and non-employed workers receive $(\mathrm{b}+\mathrm{r})$ so the free entry condition for workers will become:

$$
\frac{\lambda(M)[E(w)-\tau-(b+r)]}{[\delta+\lambda(M)]}=C_{w}\left(M_{w}\right)
$$

which, using (17), can be written as:

$$
\frac{\lambda(M)^{2}[(p-\tau)-(b+r)]}{[\delta+\lambda(M)]^{2}}=C_{w}\left(M_{w}\right)
$$

\footnotetext{
${ }^{2}$ One could also imagine a lump-sum tax on firms which can act, unsurprisingly to reduce the number of firms for which there is an efficiency argument.
} 
Inspection of (19) shows that the effect of welfare benefits is to discourage entry of workers as well as firms. This shift in labour supply cannot move us towards efficiency as it moves the WW line away from W'W'. It is possible that welfare benefits can improve efficiency (if the benefit of the shift in the FF line outweighs the cost of the shift in the WW line), but they cannot in their current form be used to attain the social optimum.

This analysis seems to support the conventional view that unemployment benefits discourage employment. However, although welfare benefits are typically modelled in the way we have just done, most unemployment benefit systems do not give out benefits unconditionally to those who are not in work - they are also required to search for work. As OECD (2000) puts it "scant attention in economic theory has traditionally been devoted to the labour market eligibility criteria for unemployment benefits".

Where welfare benefits are contingent on job search, the welfare payments are not just a disincentive to work but also an incentive to search for work. This latter effect might be expected to increase employment. ${ }^{3}$ In the current model, the simplest way to consider the impact of a job search requirement is to assume that those who are inactive do not receive the welfare payment $r$ while those who are unemployed do. Such a job search requirement drives a wedge between the utility flow when unemployed (which will be given by b+r) and the utility flow when inactive (which will be given by b). Hence, using (4) and (6) with these modifications, the entry condition for workers will become:

$$
r+\frac{\lambda(M)[(E(w)-\tau)-(b+r)]}{[\delta+\lambda(M)]}=C_{w}\left(M_{w}\right)
$$

where the first term in $r$ is the effect of the subsidy to job search.

The following Proposition shows that this simple change can be enough for us to attain the firstbest.

\section{Proposition 5}

If the unemployment benefit scheme breaks even then unemployment insurance at the level:

$$
r=\frac{\lambda(M)[p-b]\left(1-\varepsilon_{\lambda M}\right)}{[\delta+\lambda(M)]}
$$

attains the social optimum.

\footnotetext{
${ }^{3}$ There is some evidence to this effect e.g. Abbring et al (1999) for the Netherlands. Ashenfelter et al (1998) also report the results of four experiments designed to ensure that job search requirements were being met: the implication of their results is that, broadly speaking, they were.
} 
Proof: See Appendix.

The intuition for this result is that unemployment insurance plus a job search requirement can transfer resources from employers to workers (as is required for efficiency) without a leakage of resources to those individuals who do not enter the labour market which s the problem with unemployment insurance without the job search requirement.

\section{Progressive Income Taxation}

In recent years, tax credits (like the US Earned Income Tax Credit and the UK Working Families Tax Credit) have been widely used to provide incentives to work while ensuring a safety net level of income for low-wage workers. While these programmes are not always as new as claimed (the UK's WFTC is very similar to the earlier Family Credit) they are much more generous, largely funded out of the windfall gains in government tax revenue from strong economies. This makes their economic analysis a bit more complicated. On the one hand, they involve a reduction in the average tax rate on the affected workers as they are not break-even policies. On the other hand, they typically involve an increase in marginal tax rates so are formally equivalent to an increase in the progressivity of taxation. ${ }^{4}$

Let us consider the likely effect of this policy. To keep things simple, assume that only labour income is taxed (and not income received when unemployed) and that post-tax income is given by (1$\mathrm{t}) \mathrm{w}+\mathrm{t}_{0}$ if income is $\mathrm{w}$. We will assume that the income tax scheme must break even so that an increase in progressivity can be thought of as an increase in $\mathrm{t}_{0}$ together with an appropriate increase in $\mathrm{t}$. The assumption that income when unemployed is unaffected by the tax system ensures that we are simply analysing the impact of a redistribution of income among those in work.

What is the impact of progressive income taxation on the equilibrium of the economy? First, consider the lowest wage paid by employers. Workers in the lowest-wage firm must continue to be indifferent between work and unemployment so that we must have:

$$
(1-\tau) w(0)+\tau_{0}=b
$$

The expected wage must then satisfy (14) with $\mathrm{w}(0)$ as determined in (22). We can prove the following result about how the free entry and labour supply conditions are affected.

\footnotetext{
4. Of course, these policies have not been explicitly described as an increase in tax progressivity for to do so would be to expose one to the accusation of aggressive taxation policies.
} 


\section{Proposition 6}

A revenue-neutral increase in tax progressivity reduces the average wage paid by employers and received by workers: this moves the economy away from efficiency.

Proof: See Appendix.

This result might seem a bit surprising but is very simple. The lowest-wage firm can cut wages when progressivity increases as its workers are, at the initial wage, better off than before. This reduces the average wage paid by employers. If the tax system is revenue-neutral then the average wage received by workers is the same as that paid by employers, so this reduction in the average wage makes workers worse-off. Another way to think about this result is that subsidising low-wage labour encourages the payment of low wages and, in a monopsonistic labour market, employers have the market power to take advantage of this.

The actual impact of policies like EITC and WFTC are likely to be rather different from this for a number of reasons. First, they are not typically revenue-neutral: to the extent that there are ways in which the overall tax burden on labour has been reduced, they will tend to encourage labour supply and the entry of firms. Secondly, they are not directed at all segments of the population (typically they only apply to families) so the general equilibrium effects on wages may not be as large as they seem here. And the potentially undesirable side-effect could be removed if combined with a minimum wage as employers would not then be able to cut wages at the bottom end of the wage distribution: in practice this is often what happens.

\section{Restrictions On Labour Contracts}

A common form of labour market intervention is a restriction on the form of labour contracts that can be agreed between worker and employer. These vary from anti-slavery laws which prohibit adults from selling themselves into slavery, to health and safety legislation, to restrictions on the number of hours that may be worked. Economists are often particularly hostile to these types of interventions because, in a perfectly competitive labour market, there will not only be an efficiency cost from the restriction on free contracting but because they may also fail to make better-off those they aim to help as one would expect an off-setting adjustment in wages which may even make workers worse-off than they would be in the absence of the intervention (see, for example, the discussion in Summers, 1989). This section 
shows that, in a monopsonistic labour market, such restrictions can be expected to make workers better off even if wages can be freely adjusted. As we want to focus on the issue of whether these restrictions can make workers better-off we will restrict attention to the case where the numbers of workers and employers in the market is exogenously fixed. ${ }^{5}$

Consider a very stylised form of these restrictions. Suppose that workers and employers do not agree just a wage w, but also an effort level, e. Ceteris paribus, a higher level of effort means more net revenue for the employer so let us denote this by $\mathrm{p}(\mathrm{e})$ where $\mathrm{p}^{\prime}(\mathrm{e})>0$ and lower utility for the worker. Let us denote their utility function by $\mathrm{v}(\mathrm{w}, \mathrm{e})$ where $\mathrm{v}_{\mathrm{e}}(\mathrm{w}, \mathrm{e})<0$. 'e' could be interpreted as hours or how dangerous the job is or any non-pecuniary aspect to the job which workers dislike but which raises the profits of the firm.

The fact that higher paid workers tend to have jobs that are more pleasant in non-pecuniary aspects and that increasing prosperity has generally led to more pleasant and safer working conditions gives us strong reason to believe that e is a 'normal bad', that as workers get better-off they demand less of it. This amounts to the condition that:

$$
\frac{v_{w w} v_{e}}{v_{w}}-v_{w e}>0
$$

and we will assume this in what follows.

First consider what will happen in a perfectly competitive market. Employers will face an exogenously given market level of utility that they need to pay to attract any workers: let us denote this by $v_{0}$. They will choose the wage and effort to solve the problem:

$$
\max [p(e)-w] \quad \text { s.t. } \quad v(w, e) \geq v_{0}
$$

leading to the first-order condition:

$$
p^{\prime}(e)=-\frac{v_{e}(w, e)}{v_{w}(w, e)}
$$

which, together with the constraint in (24) can be solved for the optimal (w,e). Note, that this is the efficient outcome. Define $\mathrm{p}\left(\mathrm{v}_{0}\right)$ to be the maximised value of profits from (24). From the normality assumption in (23) the level of e must be decreasing in $\mathrm{b}$. Now consider what happens when a restriction $\mathrm{e} \leq \mathrm{e}^{*}$ is imposed. Denote by $\mathrm{p}\left(\mathrm{v}_{0}, \mathrm{e}^{*}\right)$ to be the level of profits when the firm is constrained in

\footnotetext{
5 Note that we are concerned with a positive issue here (the direction of the impact of the restrictions on worker utility) rather than the normative issues of efficiency which have been the subject of most of the rest of the paper. This is partly because, when e is a normal bad, one can no longer separate efficiency and distribution as can be done in the models in the rest of the paper.
} 
this way and must give workers utility $\mathrm{v}_{0}$. If the constraint is binding, the partial equilibrium effect will be that the workers are no better off while the firm is worse-off. But, it is also likely that $\mathrm{v}_{0}$ changes. For example, if we consider a free-entry equilibrium with a perfectly elastic supply of workers then, in equilibrium, we must have $\mathrm{w}=\mathrm{p}(\mathrm{e})$ so that wages will fall. And, because the perfectly competitive equilibrium is efficient, workers must lose out by the restriction. If they hate e enough, they would be prepared to accept a lower wage to obtain it without any need for government intervention. This is the standard argument used by economists against these types of intervention.

Now, let us consider what is likely to happen in a monopsonistic labour market. To consider this case, let us go back to the model described in section 1 above and modify it so that p depends on e and workers care about utility $\mathrm{v}(\mathrm{w}, \mathrm{e})$. To focus attention on whether workers can ever be made better off by these policies let us consider the market equilibrium with a fixed number of workers and firms.

First, consider the free market situation without any restrictions on e. The worst employer will give its workers utility of $\mathrm{b}$ where this is the utility obtainable when unemployed. One can then solve for the equilibrium as:

$$
\pi(u(F))=\pi(b) \frac{N(0)}{N(F)}
$$

The better firms in the labour market will not only offer a higher level of utility but also a lower level of effort.

Now, consider what happens when we impose an upper bound on the level of e that is acceptable, $\mathrm{e}^{*}$. Firms below some cut-off, point $\mathrm{F}^{*}$ will now be constrained to offer $\mathrm{e}^{*}$ while those above will be unconstrained. The worst employer will cut wages so that their workers are no better off than before i.e. they still receive utility equal to $b$. This mechanism is the usual one: the non-pecuniary aspects of the job are now more attractive so the pecuniary terms are worsened. But, as we shall see this does not mean that other workers will not be better off. Denote by $u\left(F, e^{*}\right)$ the level of utility received by workers in an employer at position $\mathrm{F}$ in the utility distribution when $\mathrm{e}^{*}$ is the maximum legal level of e. Equilibrium in the firms that are constrained by the law will be given by:

$$
\pi\left(u\left(F, e^{*}\right), e^{*}\right)=\pi\left(b, e^{*}\right) \frac{N(0)}{N(F)}
$$

and equilibrium in the unconstrained firms will be given by:

$$
\pi\left(u\left(F, e^{*}\right)\right)=\pi\left(b, e^{*}\right) \frac{N(0)}{N(F)}
$$


The cut-off between the two regimes will be given by the value of $\mathrm{F}^{*}$ which solves $\mathrm{p}\left(\mathrm{u}\left(\mathrm{F}^{*}, \mathrm{e}^{*}\right)\right)=\mathrm{p}\left(\mathrm{u}\left(\mathrm{F}^{*}, \mathrm{e}^{*}\right), \mathrm{e}^{*}\right)$ i.e. the point at which the law is just binding.

The important point is that the profits of the worst employer, $\pi\left(b, e^{*}\right)$, fall. In equilibrium, this means the profits of all other employers must also fall. For the unconstrained firms, it is obvious from (28) that this means that worker utility must rise but the following Proposition shows that the normality condition (23) means that workers in all firms except the worst must be strictly better off.

\section{Proposition 7}

A reduction in e that binds in some firm and does not make positive profits impossible will always make all workers except those in the worst employer strictly better-off.

Proof: See Appendix.

This is a strong result as it shows that more restrictions on labour contracts that favour workers will always make them better off. But the result does rely on the assumption of fixed numbers of firms and workers. As profits fall, the number of firms will be reduced and this will tend to make the workers worse-off providing an offsetting effect. But as worker utility rises this will also encourage the entry of workers. But from our earlier analysis policies that reduce profits and increase worker utility do correct the failure in the free market.

One might want an analysis of the efficiency aspects of the intervention. That is made difficult as, with e a 'normal bad', one cannot separate distribution and efficiency as is done in the rest of the paper. Given the level of utility offered by an employer in a monopsonistic labour market, e will be at the efficient level. But, the level of utility offered is inefficiently low which, given the normality condition, implies that effort is too high compared to the first-best. This means that it is unclear whether the restrictions on labour contracts will increase or reduce efficiency.

\section{Conclusions}

This paper has used a simple model of a monopsonistic labour market to provide a unified treatment of a range of labour market policies. The basic result is that average wages will tend to be too low in monopsony and there are a variety of policies tools that could be used to remedy the situation: minimum wages, trade unions, unemployment benefits (with a job search requirement), restrictions on employment 
contracts. If labour markets are monopsonistic there is no necessary trade-off between equity and efficiency for many of these policies though one should not take this to mean that the policies are universally good: typically there is an optimal level of intervention beyond which they will cause efficiency losses. That labour markets are fundamentally monopsonistic has not been argued here (see Manning, 2001 , for this argument developed at length) but it is fundamentally plausible because there are sizable frictions in labour markets.

The theoretical arguments in this paper are no substitute for empirical research into the impact of the policies described here. Indeed, empirical research is more important because one no longer has the certainty that particular policies are bad that comes from a strong belief in the underlying correctness of the perfectly competitive model. But, hopefully, these theoretical arguments can give some support to those whose approach to policy is more pragmatic than ideological. 
Figure 1

The free entry equilibrium

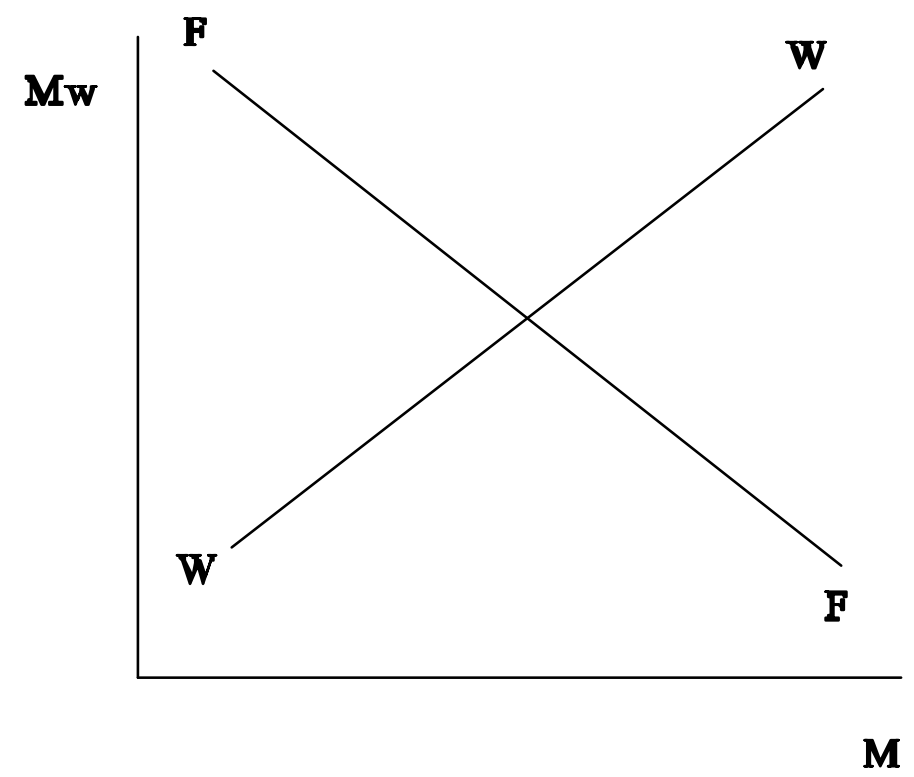


Figure 2

The free market and efficient equilibria

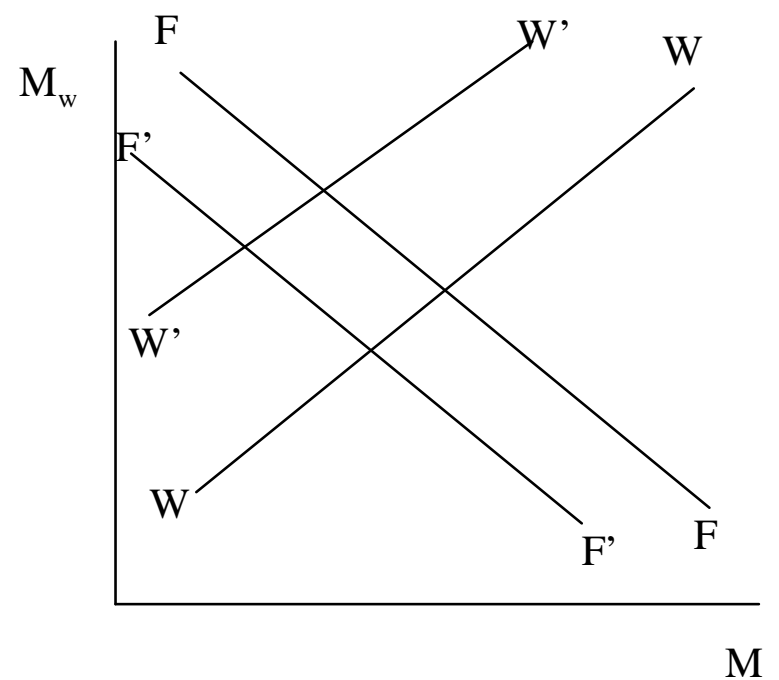




\section{Appendix}

\section{Proof of Proposition 1}

\section{The behaviour of workers}

The behaviour of workers in this labour market is very simple. An employed worker will move to another job whenever a wage offer above the current wage is received. An unemployed worker will accept a job whenever the wage offer received is above some reservation wage, $r$. With the assumptions made the reservation wage will simply be equal to $b$, the value of leisure. As job offers arrive at the same rate, whether employed or unemployed, the decision to accept a current job offer has no consequences for future job opportunities.

\section{Employment determination}

An employer who pays a wage w will recruit workers from among the unemployed (as long as it is larger than the reservation wage b) and from workers in other firms which pay less than w. The employer will lose workers who exit to unemployment or leave the labour force or who quit to other firms which pay higher wages. In general terms, if $s(w ; F)$ is the separation rate and $R(w ; F)$ is the recruitment rate, we must have in a steady state that:

$$
s(w ; F) N(w ; F)=R(w ; F)
$$

so that $\mathrm{N}(\mathrm{w} ; \mathrm{F})$ is the level of employment at which the flow of recruits equals the flow of separations. In deriving $\mathrm{N}(\mathrm{w} ; \mathrm{F})$, a very useful result is that there is no mass point in any equilibrium wage distribution (see Burdett and Mortensen, 1998, for a proof). The separation rate in a firm that pays $\mathrm{w}$ is:

$$
s(w ; F)=\delta+\lambda[1-F(w)]
$$

as workers leave for non-employment at a rate d, receive other job offers at a rate ? and a fraction [1$\mathrm{F}(\mathrm{w})]$ of these offers are better than their current wage.

Deriving the flow of recruits to the firm is slightly more complicated. It is helpful to first derive the employment rate and the distribution of wages across workers. 


\section{The employment rate}

The employment rate, $\mathrm{n}$, will simply be given by:

$$
n=\frac{\lambda}{\delta+\lambda}
$$

as workers leave employment for unemployment at a rate $\mathrm{d}$ and obtain jobs at a rate?

\section{The distribution of wages across workers}

We have denoted the distribution of wages across firms by $\mathrm{F}(\mathrm{w})$. This is not the same as the distribution of wages across workers as the systematic search by workers for better-paying jobs means that they will concentrate in higher-wage firms. Let us denote by $\mathrm{G}(\mathrm{w} ; \mathrm{F})$ the fraction of employed workers receiving a wage $\mathrm{w}$ or less when the wage offer distribution is $\mathrm{F}$.

In total there will be $\mathrm{Gn}$ of workers in this situation. They will leave at a rate $[\mathrm{d}+?(1-\mathrm{F})]$ to be replaced at a rate ?F(1-n) of workers from unemployment. Equating inflows and outflows we then have:

$$
[\delta+\lambda(1-F)] G n=\lambda F(1-n)
$$

Using the fact that $n=? /(d+?)$, re-arrangement of this leads to:

$$
G=\frac{\delta F}{(\delta+\lambda) F}
$$

From inspection of (33) one can see that $\mathrm{G}(\mathrm{w} ; \mathrm{F})<\mathrm{F}$ for $0<\mathrm{F}<1$ which implies that workers are concentrated in the better-paying jobs, implying that such firms must have a higher level of employment. This is easy to understand: higher-wage firms have lower separation rates and higher recruitment rates so that they have more workers.

\section{The flow of recruits to a firm}

Now let us go back to deriving the level of employment in a firm that pays w. Recruits to this firm will come from unemployment and those employed in lower-wage jobs. There are ?(1-n) $\mathrm{M}_{\mathrm{w}}$ unemployed worker who receive job offers which are shared equally over the $\mathrm{M}_{\mathrm{f}}$ firms so that the flow of unemployed recruits to the firm will be ?(1-n) $M_{w} / M_{\mathrm{f}}=?(1-n) / M$. Similarly, there are ?nG(w;F) $M_{w}$ workers currently earning less than $w$ who get job offers which again are spread over the $\mathrm{M}_{\mathrm{f}}$ firms. So, the total flow of recruits to a firm that pays $\mathrm{w}$ is given by: 


$$
R(w ; F)=\frac{\lambda}{M}[1-n+n G(w ; F)]=\frac{\delta \lambda}{M[\delta+\lambda(1-F)]}
$$

where the second equality follows from the use of (31) and (33). Combining (29), (30), and (34) we finally have the following expression:

$$
N(w ; F)=\frac{\delta \lambda}{M[\delta+\lambda(1-F(w))]^{2}}
$$

for the supply of labour to the firm. Note that the position of the firm in the wage offer distribution is a sufficient statistic for the supply of labour to the firm.

\section{Expected profits}

Expected profits can be written as:

$$
E(\pi)=E([p-w(F)] N(F))=[p-E(w)] E(N)
$$

where $\mathrm{E}(\mathrm{N})$ is the average level of employment in a firm. This must be the employment rate as given by (31) divided by the ratio of firms to workers. This gives (3).

\section{The value of being unemployed}

Denote by $\mathrm{V}(\mathrm{F})$ the value of being employed at position $\mathrm{F}$ in the wage distribution and by $\mathrm{V}^{\mathrm{u}}$ the value of being unemployed. These value functions must be given by:

$$
\delta_{r} V(F)=w_{c}(F)+\delta_{u}\left(V^{u}-V(F)\right)+\lambda \int_{F}^{1}[V(f)-V(F)] d f
$$

and:

$$
\delta_{r} V^{u}=b+\lambda \int_{0}^{1}\left[V(f)-V^{u}\right] d f=b+\lambda\left[V(0)-V^{u}\right]+\lambda \int_{0}^{1}[V(f)-V(0)] d f
$$

Differentiate (37) to yield:

$$
V(F)=\frac{w^{\prime}(F)}{\delta+\lambda(1-F)}
$$

Now integrate the term under the integral sign in (38) by parts to obtain:

$$
\lambda \int_{0}^{1}[V(f)-V(0)] d f=\lambda \int_{0}^{1} V^{\prime}(f) \cdot[1-f] d f=\int_{0}^{1} \frac{\lambda(1-f) w_{c}^{\prime}(f) d f}{\delta+\lambda(1-f)}
$$

Now, taking differences of (37) and (38) we have that:

$$
\left[V(0)-V^{u}\right]=\frac{w_{c}(0)-b}{\delta+\lambda}
$$


Using (38), (40) and (41) leads to the following expression for $\mathrm{V}^{\mathrm{u}}$ :

$$
\delta_{r} V^{u}=b+\frac{\lambda}{\delta+\lambda}\left[w_{c}(0)-b\right]+\int_{0}^{1} \frac{\lambda[1-f] w_{c}^{\prime}(f) d f}{\delta+\lambda(1-f)}
$$

Integrating the final term in (42) by parts we have:

$$
\delta_{r} V^{u}=b-\frac{\lambda}{\delta+\lambda} b+\int_{0}^{l} \frac{\delta \lambda}{M[\delta+\lambda(1-f)]^{2}} w_{c}(f) d f
$$

Using (1) and (2) this can be written as (4) as the integral in (43) can be written as $\int_{0}^{1} N(f) w_{c}(f) d f$.

\section{Proof of Proposition 2}

Defining a multiplier $\mu$ for the constraint $\mathrm{MM}_{\mathrm{w}}=\mathrm{M}_{\mathrm{f}}$, the first-order conditions for the maximisation of (9) with respect to $\left(\mathrm{M}_{\mathrm{w}}, \mathrm{M}_{\mathrm{f}}, \mathrm{M}\right)$ can be written as:

$$
\begin{gathered}
\frac{\lambda(M)[p-b]}{[\delta+\lambda(M)]}-C_{w}\left(M_{w}\right)-\mu M=0 \\
-C_{f}\left(M_{f}\right)+\mu=0 \\
\frac{\delta \lambda^{\prime}(M)[p-b]}{[\delta+\lambda(M)]^{2}}-\mu_{M_{w}}=0
\end{gathered}
$$

Re-arranging these leads to (9) and (10).

Comparing these with the entry conditions (5) and (7) allows us to derive (11) as the efficient level of average wages.

\section{Proof of Proposition 4}

As only the employed pay taxes and the unemployed receive welfare benefits, the break-even constraint for the scheme can be written as:

$$
\frac{\lambda \tau}{\delta+\lambda}=\frac{\delta r}{\delta+\lambda}
$$

(47) implies the free entry condition for workers (20) implies can be written as: 


$$
\frac{\lambda(M)[E(w)-b]}{[\delta+\lambda(M)]}=C_{w}\left(M_{w}\right)
$$

which is, given the level of expected wages, independent of the welfare system. The only issue is whether a suitable choice of the welfare system can get the expected wage at the appropriate level. This amounts to the condition that the lowest wage is set at the efficient level which requires that:

$$
w(0)=b+\tau+r=p-\frac{\delta}{\delta+\lambda} \varepsilon_{\lambda M}(p-b)
$$

Re-arrangement of (49) and use of (47) leads to (21).

\section{Proof of Proposition 6}

From (14) and (22) we have that:

$$
E(w)=p-\frac{\delta}{\delta+\lambda}\left[p-\frac{b-\tau_{0}}{1-\tau}\right]
$$

An increase in progressivity raises both $\tau_{0}$ and $\tau$ which reduces the average wage. This encourages the entry of firms. As the tax system simply redistributes among workers in employment the expected wage for workers must also be given by (50) so that entry of workers is discouraged.

\section{Proof of Proposition 7}

As $\mathrm{p}\left(\mathrm{b}, \mathrm{e}^{*}\right)$ must be increasing in $\mathrm{e}^{*}$ if it binds, a reduction in e must reduce $\mathrm{p}\left(\mathrm{b}, \mathrm{e}^{*}\right)$. For $\mathrm{F}>\mathrm{F}^{*}$, it is obvious that $\mathrm{u}(\mathrm{F})$ must then increase. For $\mathrm{F}<\mathrm{F}^{*}$ we have that:

$$
\pi_{u}\left(u\left(F, e^{*}\right), e^{*}\right) \frac{\partial u\left(F, e^{*}\right)}{\partial e^{*}}+\pi_{e}\left(u\left(F, e^{*}\right), e^{*}\right)=\pi_{e}\left(b, e^{*}\right) \frac{N(0)}{N(F)}
$$

Re-arranging this can be written as:

$$
\frac{\pi_{u}\left(u\left(F, e^{*}\right), e^{*}\right)}{N(F) \pi\left(u\left(F, e^{*}\right), e^{*}\right)} \frac{\partial u\left(F, e^{*}\right)}{\partial e^{*}}=\frac{\pi_{e}\left(b, e^{*}\right)}{\pi\left(b, e^{*}\right)}-\frac{\pi_{e}\left(u\left(F, e^{*}\right), e^{*}\right)}{\pi\left(u\left(F, e^{*}\right), e^{*}\right)}
$$

so that the sign of $\partial \mathrm{u}\left(\mathrm{F}, \mathrm{e}^{*}\right) / \partial \mathrm{e}^{*}$ depends on the sign of $\partial^{2} \log [\mathrm{p}(\mathrm{u}, \mathrm{e})] / \partial \mathrm{e} \partial \mathrm{u}$. We know that this is positive because of the inferiority of e so that $\partial \mathrm{u}\left(\mathrm{F}, \mathrm{e}^{*}\right) / \partial \mathrm{e}^{*}>0$. This proves the Proposition. 


\section{References}

Abbring, J., van den Berg, G. and van Ours J. (1999), 'The Effect of Unemployment Insurance Sanctions on the Transition Rate from Unemployment to Employment', Tinbergen Institute, http://www.xs4all.nl/ eabbring/papers.htm\#p:sanctions.

Ashenfelter, O., Ashmore, D. and Deschenes, O. (1998), 'Do Unemployment Insurance Recipients Actively Seek Work? Randomized Trials in Four U.S. States', Working Paper, Princeton IR Section.

Burdett, K. and Mortensen, D. (1998), 'Wage Differentials, Employer Size, and Unemployment', International Economic Review, 39, 257-273.

Hosios, A. (1990), 'On the Efficiency of Matching and Related Models of Search and Unemployment', Review of Economic Studies, 57, 279-298.

Machin, S. and Manning, A. (1997), 'The Structure of Wages in What Should be a Competitive Labour Market', Working Paper, Centre for Economic Performance, London School of Economics.

Manning, A. (2001), 'Monopsony in Motion', Centre for Economic Performance, London School of Economics, forthcoming.

OECD (2000), 'Eligibility Criteria for Unemployment Benefits', OECD Employment Outlook, June 2000, 129-153.

Pissarides, C. (1990), Equilibrium Unemployment Theory, Blackwell: Oxford.

Summers, L. (1989), 'Some Simple Economics of Mandated Benefits', American Economic Review, 79, 177-183. 


\section{CENTRE FOR ECONOMIC PERFORMANCE Recent Discussion Papers}

513 H. Steedman

512 R. Gomez M. Gunderson

N. Meltz

511 G. Duranton

D. Puga

510 P.-P. Combes

G. Duranton

509 R. Griffith

S. Redding

J. Van Reenen

508 H. G. Overman

S. Redding

A. J. Venables

507 A. J. Venables

506 R. Dickens

D. T. Ellwood

505 M. Ghell

504 A. Charlwood

503 D. Marsden

S. French

K. Kubo

502 S. Nickell

L. Nunziata

W. Ochel

G. Quintini
Benchmarking Apprenticeship: UK and Continental Europe Compared

From 'Playstations' to 'Workstations': Youth Preferences for Unionisation

From Sectoral to Functional Urban Specialisation

Labor Pooling, Labour Poaching, and Spatial Clustering

Measuring the Cost Effectiveness of an R\&D Tax Credit for the UK

The Economic Geography of Trade, Production and Income: A Survey of Empirics

Geography and International Inequalities: the Impact of New Technologies

Whither Poverty in Great Britain and the United States?

The Determinants of Changing Poverty and Whether Work Will Work

Fixed-Term Contracts and the Duration Distribution of Unemployment

Influences on Trade Union Organising Effectiveness in Great Britain

Does Performance Pay De-Motivate, and Does It Matter?

The Beveridge Curve, Unemployment and Wages in the OECD from the 1960s to the 1990s 
$501 \quad$ S. Redding

M. Vera-Martin

$500 \quad$ Edited by

D. Marsden and

H. Stephenson

499
A. Manning

498

A. Charlwood

497
M. Keil
D. Robertson
J. Symons

496 A. Di Liberto

J. Symons

495 S. Redding

A. J. Venables

494 A. Bryson

493

D. Metcalf

492 R. Gomez

S. M. Lipset

N. Meltz

491 S. Burgess

J. Lane

D. Stevens

$490 \quad$ S. Burgess

S. Profit

489
Factor Endowments and Production in European Regions

Labour Law and Social Insurance in the New Economy: A

Debate on the Supiot Report

A Generalised Model of Monopsony

Why Do Non-Union Employees Want to Unionise?

Evidence from Britain

Minimum Wages and Employment

Education and Italian Regional Development

Economic Geography and International Inequality

Union Effects on Managerial and Employee Perceptions of Employee Relations in Britain

British Unions: Dissolution or Resurgence Revisited

Frustrated Demand for Unionisation: the Case of the

United States and Canada Revisited

Jobs, Workers and Changes in Earnings Dispersion

Externalities in the Matching of Workers and Firms in

Britain

Nominal Wage Rigidity and the Rate of Inflation

To order a discussion paper, please contact the Publications Unit Tel 02079557673 Fax 02079557595 Email info@cep.lse.ac.uk Web site http://cep.lse.ac.uk 